\title{
Desempenho produtivo de bovinos de diferentes grupos raciais, castrados e não-castrados, em fase de terminação
}

\author{
[Productive performance of castrated or non-castrated bovines of different breeds at finishing phase] \\ A. Vittori ${ }^{1}$, A. Gesualdi Júnior ${ }^{2 *}$, A.C. Queiroz ${ }^{1}$, F.D. Resende ${ }^{3}$, G.F. Alleoni ${ }^{4}$, \\ A.G. Razook, , L.A. Figueiredo ${ }^{5}$ \\ ${ }^{1}$ Departamento de Zootecnia - UFV - Viçosa, MG \\ ${ }^{2}$ Parque de Alta Tecnologia do Norte Fluminense - TECNORTE \\ Av. Alberto Lamego, 2000 \\ 28013-602 - Campos dos Goytacazes, RJ \\ ${ }^{3}$ APTA - Regional Alta Mogiana - Colina, SP \\ ${ }^{4}$ Instituto de Zootecnia - Nova Odessa, SP \\ ${ }^{5}$ Instituto de Zootecnia - CAPTA Bovinos de Corte - Sertãozinho, SP
}

\begin{abstract}
RESUMO
Utilizaram-se 86 bovinos, castrados e não-castrados, com peso médio de 329kg e 20 meses de idade, sendo 12 Gir, 20 Guzerá, 20 Nelore e 20 Caracu - todos selecionados para peso aos 378 dias de idade (P378) - e 14 Nelore controle-selecionados com base no diferencial de seleção nulo para P378. A dieta, usada na relação volumoso:concentrado de 60:40 na matéria seca (MS), continha 14,8\% de proteína bruta na MS e silagem de milho. O delineamento experimental utilizado foi o inteiramente ao acaso, em esquema fatorial 5 x 2 (grupos genético e classe sexual). Os ganhos médios diários de $1,51 \mathrm{~kg}$ para Nelore seleção e 1,53kg para Guzerá foram semelhantes e maiores que os dos demais grupos genéticos, os quais não diferiram entre si. Não houve diferenças de ganho entre animais castrados e não-castrados. O consumo de $\mathrm{MS}$ em $\mathrm{kg} / \mathrm{dia}$ foi maior para Nelore, Guzerá e Caracu selecionados $(10,30 ; 10,04$ e 10,71 kg/dia, respectivamente), e os valores para os demais foram semelhantes entre si. A eficiência bionutricional foi pior para a raça Caracu $(2,13)$ e melhor para Nelore controle (1,58). Os animais Caracu precisaram de maior tempo em confinamento (133 dias) para atingir $4 \mathrm{~mm}$ de espessura de gordura subcutânea, sendo os valores para as demais raças próximos entre si.
\end{abstract}

Palavras-chave: bovino, confinamento, eficiência bionutricional

\begin{abstract}
Eighty-six castrated and non-castrated, approximately 20-month-old bovines averaging $329 \mathrm{~kg}$ were used. They were 12 Gyr, 20 Nellore, 20 Guzerá and 20 Caracu, which were submitted to selection to weight at 378 dayold (W378) and 14 control Nellore - chosen based on nule selection differential to W378. The diet contained $14.8 \%$ of crude protein in dry matter (DM) and corn silage was used in the ratio of 60:40\% forage: concentrate in DM basis. A completely randomized design in a $5 \times 2$ factorial arrangement (breed and sexual condition) was used. The average daily gain of $1.51 \mathrm{~kg}$ and $1.53 \mathrm{~kg}$ for selected Nellore and Guzerá did not differ, however surpassed those from the other breeds, which did not differ from each other. There was no difference between castrated and non-castrated animals. The dry matter intake in $\mathrm{kg} /$ day were higher for selected Nellore, Guzerá and Caracu $(10.30 ; 10.04$ and $10.71 \mathrm{~kg} /$ day, respectively) and the values observed for the two other groups did not differ from each other. The bionutritional efficiency was worse for Caracu (2.13) and better for control Nellore (1.58). Caracu needed to remain in feeding 133 days longer to reach $4 \mathrm{~mm}$ of subcutaneous fat thickness. The time in feeding for the others groups were similar.
\end{abstract}

Keywords: cattle, bionutritional efficiency, feedlot

Recebido em 20 de junho de 2005

Aceito em 24 de setembro de 2007

* Autor para correspondência (corresponding author)

E-mail: anaton@uenf.br 


\section{INTRODUÇÃO}

O Brasil detém, atualmente, a posição de maior exportador mundial de carne bovina. Para se alcançar esse resultado, cita-se a prática do confinamento, cuja viabilidade econômica depende de planejamento, disponibilidade e custo de animais e garantias de produção de alimentos volumosos e concentrados.

Estudos têm mostrado diferenças no consumo de alimento, no ganho de peso vivo e na conversão alimentar entre Bos taurus, Bos indicus e seus mestiços (Van Oltjen et al., 1993; Williams et al., 1995; Restle et al., 1996). Há indicações de que os zebuínos apresentam maior eficiência alimentar em forragens de baixa qualidade, enquanto os taurinos têm sido mais eficientes em dietas com alta porcentagem de grãos (Essig, 1995, citado por Nardon, 1998). Essas respostas são importantes, pois a pecuária brasileira tem evoluído ultimamente, e uma das ferramentas utilizadas para isto é a seleção das raças zebuínas, fator que tem proporcionado melhorias no desempenho de populações rústicas de bovinos

A castração de animais destinados ao abate é tradicionalmente realizada no Brasil, por motivos econômicos e devido à exigência de muitos frigoríficos, sob a alegação de que melhora a qualidade da carcaça, a conservação e o aspecto da carne. Com relação ao desempenho dos animais, as pesquisas mostram que animais inteiros crescem mais rapidamente: cerca de $17 \%$ utilizam o alimento mais eficientemente, cerca de $13 \%$ e apresentam ganho de peso diário superior ao dos castrados (Field, 1971).

Segundo Silva (2000), o nível nutricional dos animais influencia a utilização da castração, pois, quando o plano nutricional é alto e o abate ocorre antes dos 24 meses, a castração é desnecessária. Ainda segundo o autor, esse procedimento é importante para animais abatidos tardiamente, pois favorece o manejo, a engorda e a qualidade.

Objetivou-se, com este trabalho, avaliar o consumo, a conversão alimentar, a eficiência bionutricional, o ganho médio diário de peso vivo, o tempo de confinamento e a idade de abate de bovinos castrados e não-castrados de cinco grupos genéticos: Gir, Guzerá, Nelore e Caracu, submetidos à seleção para peso aos 378 dias de idade, e Nelore controle.

\section{MATERIAL E MÉTODOS}

O experimento foi realizado no período de junho a novembro de 2001. Foram utilizados 86 animais, nascidos em 1998, e com idade inicial média de 20 meses, provenientes da $18^{\text {a }}$ progênie dos rebanhos de Sertãozinho, SP. Utilizaram-se 12 animais Gir, 20 Guzerá, 20 Nelore e 20 Caracu, todos submetidos à seleção para peso aos 378 dias de idade (P378) e amostrados ao término da prova de ganho de peso de 1999, realizada no Instituto de Zootecnia de Sertãozinho-SP, além de 14 Nelore-controle, selecionados com base no diferencial de seleção nulo para P378, com a mesma origem dos já citados. Do total de animais de cada grupo genético, metade foi castrada logo após o final da prova de ganho de peso, em outubro.

Após um período de adaptação de 28 dias, em que todos os animais receberam a ração utilizada no período experimental, o confinamento foi iniciado, em junho de 2001, sendo sua duração determinada pelo tempo de acabamento dos animais. Quando a média da espessura de gordura subcutânea dos animais, por baia, alcançava o valor de $4 \mathrm{~mm}$, os animais eram abatidos. $\mathrm{O}$ abate do último lote ocorreu em novembro de 2001 .

Os animais foram distribuídos aos pares, por grupo genético e categoria sexual, aleatoriamente, em baias de $30 \mathrm{~m}^{2}$, sendo $8 \mathrm{~m}^{2}$ de área coberta e piso concretado, provida de comedouro e bebedouro de concreto.

A dieta experimental continha $14,8 \%$ de proteína bruta e proporção volumoso:concentrado de 60:40 na matéria seca (MS), contendo silagem de milho como único volumoso. A ração experimental foi calculada com base nas exigências nutricionais propostas pelo NRC (Nutrient..., 1996), para ganho de peso vivo estimado de 1,0kg/animal/dia.

Os ingredientes usados na mistura do concentrado foram: fubá de milho, 76,7\%; farelo de algodão, $19,0 \%$; uréia, $1,8 \%$; calcário calcítico, $1,50 \%$; e mistura mineral, $1,00 \%$. 
Os alimentos foram fornecidos à vontade duas vezes ao dia, às 7 e 16 horas. As quantidades fornecidas foram adequadas ao consumo, para que houvesse sobras, em torno de $5 \%$ do oferecido. Semanalmente, foram coletadas amostras de silagem, concentrado e sobras, para se obter as compostas por período de 28 dias, que posteriormente eram secas em estufas de ventilação forçada a $55^{\circ} \mathrm{C}$, moídas a $1 \mathrm{~mm}$, identificadas, embaladas e acondicionadas para as posteriores análises bromatológicas.

Nas amostras de alimentos fornecidos e sobras, foram determinados os teores de matéria seca, matéria orgânica, proteína bruta, fibra em detergente neutro, matéria mineral e extrato etéreo. As análises foram realizadas segundo as marchas analíticas descritas por Van Soest et al. (1991) e Silva e Queiroz (2002) (Tab. 1).

Tabela 1. Teores de matéria seca (MS), matéria orgânica (MO), proteína bruta (PB), fibra em detergente neutro (FDN), extrato etéreo (EE) e matéria mineral (MM) do concentrado e da silagem de milho

\begin{tabular}{lcccc}
\hline \multicolumn{1}{c}{ Nutriente } & Concentrado & Farelo de algodão & $\begin{array}{c}\text { Fubá de } \\
\text { milho }\end{array}$ & $\begin{array}{c}\text { Silagem de } \\
\text { milho }\end{array}$ \\
\hline MS (\%) & 81,21 & 81,87 & 79,45 & 31,03 \\
MO $^{1}$ & 96,75 & 94,61 & 98,86 & 95,64 \\
BB $^{1}$ & 24,60 & 40,98 & 10,94 & 8,26 \\
$\mathrm{FDN}^{1}$ & 17,31 & 33,23 & 12,11 & 47,85 \\
$\mathrm{EE}^{1}$ & 1,30 & 0,62 & 0,28 & 2,81 \\
$\mathrm{MM}^{1}$ & 3,25 & 5,39 & 1,14 & 4,36 \\
\hline
\end{tabular}

${ }_{1} \%$ na MS

No início do experimento e nos intervalos de 28 dias, os animais foram pesados, em jejum completo de 18 horas, e monitorada a espessura de gordura subcutânea por meio da ultrasonografia.

Para avaliação ultra-sonográfica, os animais foram contidos em um tronco equipado com tesoura para apreensão da cabeça. O sítio anatômico para a medida ultra-sônica da área de olho de lombo e espessura de gordura subcutânea foi entre a $12^{\mathrm{a}}$ e a $13^{\mathrm{a}}$ costelas.

Para obtenção dos valores de eficiência bionutricional (EFB), as variáveis ganho médio diário (GMD) e consumo de matéria seca (CMS) foram consideradas de forma conjunta, em uma análise bivariada, utilizando-se o procedimento MANOVA do SAS (User's..., 1989). Para complementação da análise, foi utilizada a primeira função discriminante canônica. As médias de mínimos quadrados da EFB foram obtidas com base na equação de eficiência bionutricional, extraída da matriz da soma de quadrados de tratamentos: $\mathrm{EFB}=-0,4905 *$ $\mathrm{GMD}+0,2571 * \mathrm{CMS}$

$\mathrm{O}$ delineamento experimental foi inteiramente ao acaso, em esquema fatorial 5 × 2 (grupo genético e classe sexual). Os demais dados foram interpretados estatisticamente por meio de análise de variância utilizando-se o teste F, a 5\% de probabilidade. As médias foram comparadas por meio do teste de diferença mínima significativa (DMS), também a 5\% de probabilidade, ambos utilizando o procedimento GLM do SAS (User's..., 1989).

Os dados foram analisados segundo o modelo estatístico: $Y_{\mathrm{ijk}}=\mu+\alpha_{\mathrm{i}}+\beta_{\mathrm{j}}+(\alpha \beta)_{\mathrm{ij}}+\varepsilon_{\mathrm{ijk}}$, em que:

$\mathrm{Y}_{\mathrm{ijk}}=$ variável resposta referente ao animal $\mathrm{k}$, do grupo genético i e sexo $\mathrm{j}$;

$\mu=$ constante geral;

$\alpha_{i}=$ efeito do grupo genético $\mathrm{i}$;

$\beta_{\mathrm{j}}=$ efeito da classe sexual $\mathrm{j}$;

$\alpha \beta_{\mathrm{ij}}=$ efeito da interação do grupo genético i com o sexo j;

$\mathrm{e}_{\mathrm{ijk}}=$ erro aleatório, suposto NID $\sim\left(0, \sigma^{2}\right)$

$\mathrm{i}=1$ - Gir, 2 - Guzerá, 3 - Nelore-controle, 4 -

Nelore-seleção e 5 - Caracu;

$\mathrm{j}=1$ - castrado, 2 - não-castrado.

\section{RESULTADOS E DISCUSSÃO}

Não houve interação de grupo genético e classe sexual para nenhum dos fatores estudados $(\mathrm{P}>0,05)$, assim, os efeitos foram considerados independentemente. 
$\mathrm{Na}$ Tab. 2 são apresentadas as médias de quadrados mínimos do peso vivo inicial (PVI), peso vivo de abate (PVA), consumo de matéria seca (CMS), em kg/dia e g/kg PV ${ }^{0,75}$, ganho médio diário (GMD), conversão alimentar (CA), eficiência bionutricional (EFB) e dias de confinamento (DC).
As diferenças para CMS expresso em $\mathrm{kg} / \mathrm{dia}$ foram significativas apenas para grupo genético. Observou-se maior CMS em $\mathrm{kg}$ /dia nos animais dos grupos genéticos Caracu e Nelore seleção, seguidos do Guzerá, Gir e Nelore-controle, refletidos pelo porte dos animais. Os grupos Caracu e Nelore-seleção apresentaram maiores peso vivo inicial (PVI) e peso vivo de abate (PVA).

Tabela 2. Médias de quadrados mínimos do peso vivo inicial (PVI), peso vivo de abate (PVA), consumo de matéria seca (CMS), ganho médio diário (GMD), conversão alimentar (CA), eficiência bionutricional (EFB), dias de confinamento (DC) e espessura de gordura subcutânea (EGS) dos animais de diferentes grupos genéticos e classe sexual

\begin{tabular}{|c|c|c|c|c|c|c|c|c|}
\hline \multirow[b]{2}{*}{ Item } & \multicolumn{5}{|c|}{ Grupo genético } & \multicolumn{3}{|c|}{ Classe sexual } \\
\hline & Gir & Guzerá & $\begin{array}{l}\text { Nelore- } \\
\text { controle }\end{array}$ & $\begin{array}{l}\text { Nelore } \\
\text { Seleção }\end{array}$ & Caracu & Castrado & $\begin{array}{c}\text { Não- } \\
\text { castrado }\end{array}$ & $\begin{array}{l}\text { CV } \\
(\%)\end{array}$ \\
\hline $\mathrm{PVI}^{1}$ & $309 \mathrm{c}$ & $331 b$ & $289 \mathrm{c}$ & $345 b$ & $372 a$ & $330 a$ & $328 \mathrm{a}$ & 7,62 \\
\hline $\mathrm{PVA}^{1}$ & $449 \mathrm{c}$ & $469 \mathrm{c}$ & $406 \mathrm{~d}$ & $495 b$ & $533 a$ & $447 b$ & $494 \mathrm{a}$ & 7,01 \\
\hline $\mathrm{CMS}^{1}(\mathrm{~kg} / \mathrm{dia})$ & $9,36 \mathrm{bc}$ & $10,04 \mathrm{ab}$ & $8,54 \mathrm{c}$ & $10,30 \mathrm{a}$ & $10,71 \mathrm{a}$ & $9,60 \mathrm{a}$ & $9,96 \mathrm{a}$ & 8,80 \\
\hline $\mathrm{CMS}^{2}\left(\mathrm{~g} / \mathrm{kg}^{0,75}\right)$ & 108,40 & 112,50 & 106,00 & 110,90 & 108,50 & 109,50 & 109,00 & 7,86 \\
\hline $\mathrm{GMD}^{1}$ & $1,23 \mathrm{~b}$ & $1,53 \mathrm{a}$ & $1,29 \mathrm{ab}$ & $1,51 \mathrm{a}$ & $1,26 \mathrm{~b}$ & $1,30 \mathrm{a}$ & $1,43 \mathrm{a}$ & 26,87 \\
\hline $\mathrm{CA}^{1}$ & $7,72 \mathrm{ab}$ & $6,62 b$ & $6,94 b$ & $7,32 b$ & $8,78 \mathrm{a}$ & $7,55 \mathrm{a}$ & $7,40 \mathrm{a}$ & 16,23 \\
\hline $\mathrm{EFB}^{1}$ & $1,79 \mathrm{~b}$ & $1,84 \mathrm{~b}$ & $1,58 \mathrm{c}$ & $1,94 \mathrm{~b}$ & $2,13 \mathrm{a}$ & $1,81 \mathrm{a}$ & $1,90 \mathrm{a}$ & 9,37 \\
\hline $\mathrm{DC}^{1}$ & $114 \mathrm{ab}$ & $92 b$ & $96 b$ & $104 b$ & $132 \mathrm{a}$ & $93 b$ & $122 \mathrm{a}$ & 20,89 \\
\hline $\mathrm{EGS}^{1}$ & $6,40 \mathrm{ab}$ & $7,34 \mathrm{a}$ & $6,80^{\mathrm{a}}$ & $6,89 \mathrm{a}$ & $5,44 b$ & $6,92 \mathrm{a}$ & $6,22 a$ & 35,01 \\
\hline
\end{tabular}

Médias na linha, seguidas por letras distintas, diferem entre si pelo teste de diferença mínima significativa $(\mathrm{P}<0,05)$

Em CMS, os efeitos de grupo e classe sexual não foram significativos pelo teste $\mathrm{F}(\mathrm{P}>0,05)$

O tamanho ou porte do animal é um dos fatores que influenciam o consumo de alimentos, podendo-se esperar maior consumo em animais maiores, devido à maior exigência para manutenção. Gonçalves et al. (1991) observaram que o CMS, expresso em $\mathrm{g} / \mathrm{kgPV}^{0,75}$, foi, em média, 20\% mais alto para taurinos em relação aos zebuínos, sendo que os mestiços apresentaram valores intermediários. Galvão et al. (1991) constataram que animais F1 Marchigiana $\mathrm{x}$ Nelore apresentaram maiores consumos que F1 Limousin x Nelore e Nelore, não havendo diferenças entre os dois últimos grupos. Esses autores verificaram que animais zebuínos têm menor capacidade de ingestão de alimentos, relativo aos requisitos de mantença, quando comparados a animais de raças européias.

Ao trabalhar com os mesmos grupos genéticos do presente estudo, porém oriundos da $15^{\text {a }}$ progênies, e fornecendo rações com 55\% do concentrado na matéria seca, Nardon (1998) verificou comportamento do CMS, em $\mathrm{kg} / \mathrm{dia}$, semelhante, ou seja, os animais Caracu e Neloreseleção consumiram mais que os Guzerá e Nelore-controle. Entretanto, o autor encontrou diferenças significativas também para CMS, expresso em $\mathrm{g} / \mathrm{kg} \mathrm{PV}^{0,75}$, sendo os maiores valores para o grupo Caracu $\left(94,9 \mathrm{~g} / \mathrm{kg} \mathrm{PV}^{0,75}\right) \mathrm{e}$ menor para os Nelore-controle $(87,5 \mathrm{~g} / \mathrm{kg}$ $\left.\mathrm{PV}^{0,75}\right)$.

Apesar de os animais Gir terem iniciado o confinamento com peso vivo semelhante aos Nelore-controle, seus CMS, em $\mathrm{kg} / \mathrm{dia}$, foram semelhantes aos dos Guzerá, mas, em g/kg $\mathrm{PV}^{0,75}$, foram iguais aos dos demais grupos selecionados $(\mathrm{P}>0,05)$. Apesar disso, o GMD (Tab. 2) foi menor que o dos demais grupos zebuínos, revelando que a seleção para peso aos 378 dias de idade tem proporcionado menores resultados nesta raça.

Velloso et al. (1975) relataram que o consumo de animais não-castrados foi maior do que o de castrados, mas isso não foi observado no presente estudo. Uma provável explicação é o fato de os animais terem iniciado o confinamento com PVI semelhante (Tab. 2), o que pode ter reduzido as expectativas de se encontrar diferenças no CMS. 
O PVI dos animais apresentou diferença significativa apenas para grupo genético, refletindo as diferenças inerentes a cada raça submetida ao programa de seleção com base no peso aos 378 dias de idade. Entre o Nelore selecionado e o Nelore-controle, observou-se que os primeiros tiveram peso inicial maior $(345 \mathrm{~kg})$ que os segundos $(289 \mathrm{~kg})$. Essa diferença $(56 \mathrm{~kg})$ reflete os resultados do processo de seleção para ganho em peso a que essas raças foram submetidas. Nardon (1998) também encontrou diferença de peso entre Nelore-seleção e controle, da ordem de $42,5 \mathrm{~kg}$

O PVA apresentou ainda diferença significativa entre classe sexual. Os animais não-castrados foram mais pesados ao abate que os castrados (494 vs $447 \mathrm{~kg}$ ). Considerando que os GMD foram semelhantes entre as duas classes sexuais, a superioridade dos animais não-castrados em relação aos castrados deve-se ao maior tempo de confinamento a que esses foram submetidos, uma vez que o critério de abate foi o ponto de acabamento semelhante ( $4 \mathrm{~mm}$ de espessura de gordura subcutânea).

Resultados de pesquisa mostraram que animais não-castrados cresceram mais rapidamente $\mathrm{e}$ utilizaram o alimento mais eficientemente que os castrados (Field, 1971). Entretanto, isso não ficou evidenciado neste trabalho, visto que a CA e o GMD apresentaram efeito significativo apenas para grupo genético.

A condição sexual também é um dos fatores determinantes da composição do ganho de peso, devido às influências da ação hormonal. Assim, bovinos não-castrados produzem mais proteína por unidade de energia digestível do que os castrados. Por isso, é provável que dietas com maior teor de proteína poderiam ter proporcionado maiores GMD a esses animais, como de fato ocorreu em termos numéricos.

Com relação a grupo genético, os Guzerá e Nelore-seleção apresentaram os maiores GMD, enquanto os Caracu e Gir os menores valores. Uma possível explicação é quanto à intensidade de seleção a que as raças Nelore e Guzerá foram submetidas, visto que, nos primeiros anos deste programa de seleção, as populações de Caracu e Gir utilizadas eram menores que as de Nelore e Guzerá.
A CA dos animais Caracu apresentou os maiores valores, enquanto os menores foram para Neloreseleção, Nelore-controle e Guzerá.

Da mesma forma que se analisa o CA, também para a EFB, quanto menor o valor, maior é a eficiência do animal, devido à magnitude das variáveis da equação. A EFB apresentou diferença significativa apenas para grupo genético, com o maior valor para os animais Caracu e o menor para Nelore-controle, sendo os demais intermediários (Tab. 2). Portanto, os animais Nelore-controle foram os mais eficientes bionutricionalmente. Estes resultados estão de acordo com Gregory et al. (1994), que verificaram que raças com menor peso à maturidade tenderam a ser mais eficientes na utilização de alimentos para ganho de peso vivo. Essas diferenças, tanto na CA quanto na EFB, podem ser explicadas pelo fato de que, uma vez que a composição do corpo do animal tem importância no estabelecimento das exigências de energia e proteína, o acréscimo no peso dos animais, num processo contínuo de engorda, ocasiona variações na composição e nas exigências. Dessa forma, diferentes tipos biológicos têm diferentes pontos de máxima eficiência alimentar ou de utilização da energia e proteína ingeridas (Nardon, 1998).

Ao se compararem os valores de CA com os de EFB, pode-se notar que apenas a EFB foi capaz de discriminar os Nelore-controle como sendo mais eficientes em relação aos outros grupos genéticos.

Os dias de confinamento apresentaram diferenças significativas para grupo genético e classe sexual. Os animais castrados permaneceram menos tempo em confinamento do que os não-castrados, para atingirem o mesmo ponto de acabamento ( $4 \mathrm{~mm}$ de espessura de gordura subcutânea). Nesses, a ação hormonal da testosterona, que diminui a deposição precoce de gordura, inclusive a subcutânea, fez com que os animais permanecessem mais tempo em confinamento. Além disso, houve manifestação de comportamento mais agressivo, com os animais, provavelmente, gastando mais energia para mantença.

Os animais Caracu permaneceram mais tempo em confinamento, seguidos dos Gir. Esses dois grupos genéticos foram os que apresentaram os 
menores GMD e, além disso, demoraram mais para depositar a quantidade mínima de gordura subcutânea para serem abatidos. Segundo Barbosa (1995), há correlação genética negativa entre o peso à maturidade (idade adulta) e a taxa de maturação, ou seja, o tempo que o animal leva para atingir o tamanho à maturidade.

No caso da raça Caracu, o alto PVI $(372 \mathrm{~kg}$ ) desses animais pode ter colaborado para menor GMD. Assim, recomenda-se confinar animais com peso vivo em torno de $330 \mathrm{~kg}$. Isso permite que se trabalhe com menores exigências de mantença, assim, a maior parte da energia do alimento fica disponível para produção.

Houve efeito somente de grupo genético para espessura de gordura subcutânea (EGS). Os animais Caracu apresentaram os menores valores, que foram semelhantes aos mostrados pela raça Gir, que, por sua vez, foram semelhantes aos encontrados para os demais zebuínos (Tab. 2). Normalmente espera-se que animais castrados apresentem maior EGS que os não-castrados, o que não foi verificado neste estudo, talvez porque se procurou abater os animais com mesmo grau de acabamento, ou seja, quando a leitura de ultra-som detectava o valor de $4 \mathrm{~mm}$ para EGS.

A Tab. 3 mostra os custos de produção dos animais durante o confinamento. $\mathrm{O}$ custo da arroba produzida foi semelhante entre as raças zebuínas, ficando os animais Gir com um valor ligeiramente mais alto. Os animais Caracu apresentaram valor sensivelmente maior. Comparado à média de todos os zebuínos ( $\mathrm{R} \$$ 25,62), a diferença foi de R\$ 6,35 (U\$ 2.60).

Tabela 3. Custos de produção da arroba produzida durante o confinamento de bovinos machos de diferentes grupos genéticos castrados e não-castrados

\begin{tabular}{lccccc}
\hline $\begin{array}{c}\text { Grupo } \\
\text { genético }\end{array}$ & $\begin{array}{c}\text { Custo/animal/dia } \\
\text { (U\$) }\end{array}$ & $\begin{array}{c}\text { Dias de } \\
\text { confinamento }\end{array}$ & $\begin{array}{c}\text { Ganho total de } \\
\text { carcaça, } \\
\text { em @ }\end{array}$ & $\begin{array}{c}\text { Custo/@ } \\
\text { produzida } \\
\text { (U\$) }\end{array}$ & $\begin{array}{c}\text { Custo/@ } \\
\text { produzida } \\
\text { (R\$) }\end{array}$ \\
\hline Gir S & 0,52 & 114 & 5,34 & 11,10 & 27,41 \\
Guzera S & 0,55 & 92 & 5,07 & 9,98 & 24,65 \\
Nelore S $^{1}$ & 0,57 & 104 & 5,78 & 10,25 & 25,31 \\
Nelore C $^{1}$ & 0,47 & 96 & 4,43 & 10,18 & 25,14 \\
Caracu $^{1}$ & 0,59 & 132 & 6,00 & 12,98 & 31,98 \\
\hline
\end{tabular}

$\mathrm{S}=$ seleção; $\mathrm{C}=$ Nelore

${ }^{1}$ Valores calculados multiplicando-se a média do custo/animal/dia pela média dos dias de confinamento e dividindose pela média do ganho total de carcaça em @, durante o confinamento.

O custo de produção dos animais é altamente influenciado pelo tempo que eles levam para serem abatidos. Durante a fase de terminação, essa influência é ainda maior, pois o custo das rações utilizadas é alto, devido ao uso de alta proporção de concentrado.

Os animais das raças Gir e Caracu, que apresentaram os maiores custos de produção, permaneceram mais tempo em confinamento (Tab. 2). Os demais zebuínos ficaram próximos entre si. No caso do Gir e Caracu, os GMD mais baixos (Tab. 3) contribuíram para que se estendesse o período de confinamento, assim, foi necessária maior quantidade de alimentos para eles.

\section{REFERÊNCIAS BIBLIOGRÁFICAS}

BARBOSA, P.F. Cruzamentos para obtenção do novilho precoce. In: ENCONTRO NACIONAL SOBRE NOVILHO PRECOCE, 1995. Campinas, Anais... 1995. p.75-92.

ESSIG, H.W. Physiology of digestion: Brahman, Brahman crosses vs. British and continental breeds and their crosses. Arkansas: Agricultural Experiment Station, Division of Agriculture, University of Arkansas, 1995. p.3-11. (Special Report, 167).

FIELD, R.A. Effect of castration on meat quality and quantity. J. Anim. Sci., v.32, p.849-857, 1971.

GALVÃO, J.G.; FONTES, C.A.A.; PIRES, C.C. et al. Ganho de peso, consumo e conversão alimentar em bovinos não-castrados, de três 
grupos raciais, abatidos em diferentes estádios de maturidade (estudo I). Rev. Soc. Bras. Zootec., v.20, p.494-501, 1991.

GONÇALVES, L.C.; SILVA, J.F.C.; ESTEVÃO, M.M. et al. Consumo e digestibilidade da matéria seca e da energia em zebuínos e taurinos, seus mestiços e bubalinos. Rev. Soc. Bras. Zootec., v.20, p. 384-395, 1991.

GREGORY, K.E.; CUNDIFF, L.V.; KOCH, R.M. Breed effects, dietary energy density effects, and retained heterosis on different measures of gain efficiency in beef cattle. $J$. Anim. Sci.,. v.72, p.1138-1154, 1994.

NARDON, R.F. Seleção de bovinos para desempenho: composição corporal e características de carcaça. 1998. 99f. Tese (Doutorado em Zootecnia) - Universidade Estadual Paulista, Jaboticabal, SP.

NUTRIENTS requeriments of beef cattle. 7.ed. Washington, DC: NRC, 1996. 244p.

RESTLE, J.; GRASSI, C.; FEIJÓ, G.L.D. Características das carcaças e da carne de bovinos inteiros ou submetidos a duas formas de castração, em condições de pastagem. Rev. Soc. Bras. Zootec., v.25, p. 334-344, 1996.
SILVA, F.F. Aspectos produtivos da castração de novilhos de corte. Cad. Téc. Vet. Zootec., n.33, p.68-94, 2000.

SILVA, D.J.; QUEIROZ, A.C. Análise de alimentos: métodos químicos e biológicos. 3.ed. Viçosa: UFV, 2002. 235p.

USER'S guide. Version 6.12. Cary, NC:SAS Institute,1989, v.1. 943p.

VAN OLTJEN, M.; MONTAÑO-BERMUDEZ, M.; NIELSEN, M.K. Economical and biological efficiencies of beef cattle differing in level of milk production. J. Anim. Sci., v.71, p.44-50, 1993.

VAN SOEST, P.J.; ROBERTSON, J.B.; LEWIS, B.A. Symposium: carbohydrate metodology, metabolism, and nutritional implications in dairy cattle. J. Anim. Sci., v.74, p.3583-3597, 1991.

VELlOSO, L.; BOIN, C.; ROCHA, G.L. Bovinos da raça Nelore, inteiros e castrados em confinamento. Bol. Ind. Anim., v.32, p.9-14, 1975.

WILLIAMS, C.B.; BENNETT, G.L.; KEELE, J.W. Simulated influence of postweaning production system on performance of different biological types of cattle: III. Biological efficiency. J. Anim. Sci., v.73, p.686-698, 1995. 